\title{
Microwave Hematoma Detector for the Rapid Assessment of Head Injuries
}

W. Haddad, J. Chang, T. Rosenbury, G. Dallum, P. Welsch, D. Scott, D. Duarte, V. Acevedo-Bolton 


\section{DISCLAIMER}

This document was prepared as an account of work sponsored by an agency of the United States Government. Neither the United States Government nor the University of California nor any of their employees, makes any warranty, express or implied, or assumes any legal liability or responsibility for the accuracy, completeness, or usefulness of any information, apparatus, product, or process disclosed, or represents that its use would not infringe privately owned rights. Reference herein to any specific commercial product, process, or service by trade name, trademark, manufacturer, or otherwise, does not necessarily constitute or imply its endorsement, recommendation, or favoring by the United States Government or the University of California. The views and opinions of authors expressed herein do not necessarily state or reflect those of the United States Government or the University of California, and shall not be used for advertising or product endorsement purposes.

Work performed under the auspices of the U.S. Department of Energy by the University of California Lawrence Livermore National Laboratory under Contract W-7405-Eng-48.

This report has been reproduced directly from the best available copy.

Available to DOE and DOE contractors from the Office of Scientific and Technical Information

P.O. Box 62, Oak Ridge, TN 37831

Prices available from (423) 576-8401

http:/ / apollo.osti.gov/bridge/

Available to the public from the National Technical Information Service

U.S. Department of Commerce 5285 Port Royal Rd., Springfield, VA 22161 http://www.ntis.gov/

OR

Lawrence Livermore National Laboratory

Technical Information Department's Digital Library http://www.llnl.gov/tid/Library.html 


\title{
MICROWAVE HEMATOMA DETECTOR FOR THE RAPID ASSESSMENT OF HEAD INJURIES
}

\author{
Waleed Haddad, John Chang, Tom Rosenbury, Greg Dallum, Patrick Welsch, David Scott, \\ Davianne Duarte, Viviana Acevedo-Bolton
}

\begin{abstract}
A non-invasive microwave device for the detection of epi/subdural hemorrhaging (hematoma) is under current development. The final device will be highly portable and allow real time assessment of head injuries, thereby satisfying early detection needs of the field technician as well as providing a tool for repetitious monitoring of high-risk individuals. The device will adopt the advanced technology of micropower impulse radar (MIR) which is a state of the art low cost ultra wide band (UWB) microwave radar developed here at LLNL. It will consist of a MIR transmitting and receiving module, a computer based signal processing module, and a device-to-patient signal coupling module - the UWB antenna. The prototype design is being guided by the needs of the patient and the practitioner along with the prerequisites of the technology including issues such as the specificity of the device, efficacy of diagnosis, accuracy, robustness, and patient comfort. The prototype development follows a concurrent approach which includes experiments designed to evaluate requirements of the radar and antenna design, phantom development to facilitate laboratory investigations, and investigation into the limits of adapting pre-existing non-medical MIR devices to medical applications.

This report will present the accomplishments and project highlights to date in the fiscal year 1999. Future project projections will also be discussed.
\end{abstract}

\section{INTRODUCTION}

\section{The Need}

In the United States alone, 2 million people are treated for head injuries every year. Amongst these, 500,000 people are hospitalized, 50,000 die, and 90,000 develop long term disabilities. The demographics relating to head injuries go beyond individuals involved in accidents or falls. One population study observed the relatively common occurrence of subdural hemorrhage in infant victims of physical abuse which resulted in the death or profound disability in three quarters of the cases. [S. Jayawant, et.al., 1998] [KS Quayle, et al.1997] At the other extreme, elderly people taking certain types of medication might develop weakened vascular walls in the cranium such that a relatively minor "bump on the head" will "unexpectedly" result in a comatose state. [O De Jesus, et al., 1998] [K Kato, et al., 1999] It is well known that with any intracranial hemorrhage, the time lapse between the instance of injury and the positive identification of the hemorrhage must be minimized in order to maximize the likelihood of full recovery by expediting the delivery of proper care. Any delay in the treatment of the injury will not only result in long term disabilities, but unnecessarily tax medical and economic resources. The potential benefit gained from providing a means to minimize this delay between instance of injury and definitive care is great in both civilian as well as military sectors.

\section{Time vs. Intervention}

A serious and insidious complication associated with head trauma results from the rapid development of an epidural hematoma during which the onset of meningeal arterial hemorrhage quickly results in a fatal increase of intracranial pressure, such that an alert individual can, in some cases, literally collapse while talking and die before reaching definitive care. A second but not less deadly scenario occurs with the development of subdural hematoma for which symptoms may not present themselves for hours, and on occasion weeks, after the injury. As a result, irreparable damage or possibly death can occur. The importance of carly diagnosis and active emergency management proccdures to minimizc mortality and neuralogic morbidity is well documented. [PE Stieg, et al., 1998] [KY Willman, et al. 1997]

The current technique used to identify intracranial hemorrhage is computed tomography (CT). [CS Zee, et al. 1998] Not only are trained radiologists necessary for CT image interpretations, but more importantly, CT scammers are not portable and thus diagnosis cannot be made until the injured patient is delivered to the hospital. [MG Wysoki, et al. 1998] The hematoma detector will fill time critical gap by 
providing the means to screen head injury victims in the field and offer the opportunity to minimize any unnecessary delays between the time of injury and definitive medical intervention. [MA Vogelbaum, et al., 1998]

\section{THEORY}

\section{Biological contrasts}

It is well know that biological tissues exhibit characteristic dielectric properties that change with frequency over the entire electromagnetic spectrum. In the microwave region, these variations can ultimately be attributed to the relaxation of water molecules. [C. Polk et al., 1996]. Figure 1 shows the variation in the dielectric properties for various tissues in the cranium as a function of frequency in the range from $500 \mathrm{MHz}$ to $8 \mathrm{GHz}$. It is this contrast in dielectric properties between different tissue types that will ultimately allow the hematoma detector to differentiate and diagnose the presence of hematoma. [WS Haddad,et.al.]

\section{Device theory}

The hematoma detector will adopt the advanced technology of ultra wide bandwidth impulse radar. [LY Astanin, et al., 1997] The theory and practice of using impulse radar techniques for aerial target characterization and classification as well as subsurface mine detection are well known and under continual investigation. [DT Gavel, et al., 1995] Civilian applications of impulse radar techniques include roadbed and infrastructure evaluation. [J Mast, et al. 1998] [JP Warhus, et al., 1993] [DJ Daniels, 1996]

We have elected to use ultra wide bandwidth techniques as the basis for the hematoma detector largely because of recent advances in device technology at Lawrence Livermore National Laboratory which make it possible to produce extremely compact, low power, ultra wide bandwidth pulse generators at low cost. By marrying this recently available technology to the critical needs of head injury emergency management, we believe that the potential contribution to medicine will be quite significant.

Figure 2 is presented as an aid in visualizing how ultra wideband radar can be used to assess the structure of a sample. An ultra fast pulse having a width on the order of tens of picoseconds is generated and directed onto the sample. The pulse will bc absorbed and reflectcd back towards a receiving antenna from the various tissues and their interfaces. Computer processing of the received signal can then be used to identify the tissue variations. In addition, to minimize the clutter in the received signals, various filtering methods can be incorporated to better extract the desired signal. Because the incident pulse width is so short, it will be possible to differentiate thin structures on a millimeter scale.

Figure $3 \mathrm{a}$ shows an actual CT image of a large epidural hematoma. Figure $3 \mathrm{~b}$ shows a conceptualized schematic of one method of how the neural scanner will be able to sense the hematoma. Specifically, the separation of the dura from the meningeal wall will be observed as a delayed echo response of the signals reflecting off of the skull and the dura. In the case of subdural hematoma where there is no separation between the dura from the menengial wall, it is expected that the hematoma will have significant dielectric property changes due to blood pooling and clot formation and can thus be characterized.

\section{Device Function}

The first generation of the hematoma detector will have a compact hand held ultra wide band antenna that will be manually scanned over the victim's head. The signal generator will emit ultra wide band microwave pulses with power levels orders of magnitude less than those of hand held cellular phones. The same emitting antenna will also be used as a receiver via an ultra wide bandwidh directional coupler. The received signal will be digitally sampled and stored on a laptop computer. The received pulses will be distorted by parameters such as tissuc absorption and reflections at interfaces. As the signal is reccived, differential signal analysis with known signal characteristics will be used to evaluate the presence of hematoma. Should the acquired signal correlate well with known hematoma signatures, a notification will be given to the operator.

While the final mass produced hematoma detector will be built around compactness, portability, ease of use, robustness, and low cost, the developmental stages will require the highest degree of flexibility in parameter control and diagnostics as well as state of the art instrumentation. A laboratory prototype system based on modular components is under construction for use in development and optimization of the 
hematoma detector. The prototype will consist of an impulse transmitting and receiving module, a computer based signal processing module, and the ultra wide bandwidth antenna. A firm understanding of the ultra wide bandwidth antenna is critical for 1) transmitting the bandwidth necessary to exploit impulse radar techniques, 2) optimizing signal detectability by maximizing the signal to noise/clutter ratio.

\section{PROGRESS}

The final goal of this project is to deliver a clinical trial ready hematoma detector prototype and to initiate human trials. The following milestones have been achieved to date:

1) Performed preliminary experimental demonstration of concept

2) developed an estimate of the dimensions of the smallest detectable hematoma

3) built and characterized the prototype "hematoma" antenna

4) developed a procedure for phantom cranium fabrication

5) built ( $90 \%$ complete) instrument based impulse radar which provides full control of scanning parameters such as the range resolution, the antenna testing capability, the scanning rate, range gating control, and modularization

6) adapted pre-existing MIR (2 antennae version) for phantom testing and data acquisition driver development

7) developed a preliminary business plan

8) submitted patent disclosure

\section{Demonstration of Concept}

The preliminary demonstration of concept has been established through recent benchtop experimentation internally funded by LLNL. Images showing the experimental setup are presented in Figure 4 and Figure 5, and plots of the results are also given in Figure 5. The human cranium was simulated by available phantom materials that have dielectric properties similar to those tissues in the cranium. Specifically, a plastic bowl was used to represent the low loss dielectric properties associated with bone (skull). Gelatin was used to represent the brain matter. A small plastic bag filled with red dyed water placed along the wall of the bowl simulated the hematoma. An existing micropower impulse radar developed at LLNL for other purposes was used to send and receive the impulse signal in these carly tests. The received signal was stored via a data acquisition card, processed, and displayed on a laptop computer. Figure 5 shows the results of these feasibility tests. The top images represent the scenario in which the 'hematoma' is absent. The graph reflects the received relative amplitude versus time lapsed. Note the minor amplitude variation that might be attributed to the thickness of the plastic bowl. In the bottom figure, once the 'hematoma' was introduced, the received signal showed significant amplitude variation as a result of the dielectric properties of the hematoma.

Based on these preliminary results and some basic theoretical calculations, estimates of the detector resolution are on the order of $1 \mathrm{~cm}-3 \mathrm{~cm}$ (transverse), $1 \mathrm{~mm}-5 \mathrm{~mm}$ (depth), depending upon the pulse width and the antenna characteristics. These values suggest that the minimum detectable volume is on the order of $1.5 \mathrm{ml}$. These are very encouraging values in view of clinical observations that hematoma volumes of over $150 \mathrm{cc}$ can be compatible not only with survival but with low morbidity. (S. Paterniti, et al., 1998) Although this demonstration of concept investigation using very simple phantoms indicates high probability of success, a more thorough evaluation and understanding of the technique must be made in complex phantoms that will more realistically reflect anatomical properties.

\section{Prototype "hematoma" antenna development and fabrication}

The hematoma antenna design is governed by factors that include not only signal coupling but signal isolation from background clutter and motion artifacts which will be of great concern during field opcrations. Further, it is desired to have the antenna confine the transmitted signal to a small region in order to maximize spatial resolution. These goals can be accomplished through the use of a cone shaped interface or "nozzle". The prototype hematoma antenna is shown in Figure 6a. The antenna has been preliminarily characterized by performing $S_{11}$ measurements using the HP 8510 network analyzer from $45 \mathrm{MHz}-18 \mathrm{GHz}$. Measurements were taken with and without a saline bolus at the coupling interface. Figure $6 \mathrm{~b}$ shows the characterization results. Note that from $6 \mathrm{GHz}$ and higher, the resulting $\mathrm{S}_{11}$ showed a 
greater than $5 \mathrm{~dB}$ signal coupling although the reflection characteristics below $6 \mathrm{GHz}$ suggests the need for improvement in signal coupling. The initial characterization data shows that this prototype antenna provides a promising step for the final design.

\section{Instrument based impulse radar design and development}

The construction of an instrument based impulse radar system dedicated for medical interrogation has been initiated and is $90 \%$ complete. This effort has been a collaboration between the Medical Technology Program and the MIR development program. The goal of the instrument based micropower impulse radar is to provide a test system which offers full control of scanning parameters such as the range resolution, the antenna testing capability, the scanning rate, range gating control, and modularization. With the flexibility of controlling various signal parameters, it will provide the opportunity to design the final MIR device based upon signal characteristics unique to biological interrogations. Figure 7 and Figure 8 show the current version of the bench top instrument. Except for two 120ps impulse sources made by the MIR group, the bench top device is constructed from off the shelf commercial components. National Instrument's GPIB drivers were developed for the control of the device. Current efforts have been placed on optimizing the data acquisition of the signals for improved range scanning capability, dynamic range, and signal conversion.

\section{Phantom cranium development and fabrication}

In preparation for human testing, the use of phantom human head models provides the best means to develop and characterize the detector. Several specialized head phantoms were produced with adjustable hematoma dimensions using both commercially available as well as custom fabricated materials for this purpose. These models of the human head exhibited similar dielectric properties over the electromagnetic spectrum of interest to those reported in existing literature.[Kraszewski and Hartsgrove, 1986],[

Kobayashi, et al., 1993] Preliminary experiments on these phantoms used earlier generation MIR devices. National Instruments Labview drivers were developed specifically for control and data acquisition. These experiments provided baseline quantification and correlation between radar signal strength and hematoma size. Figure 9 shows a graphical representation of the head phantom. Figure 10 shows the background noise level of the pre-existing impulsc radar system. The abscissa corresponds to the normalized range of the radar. Figure 11a-11d show processed signals for hematomas of different sizes. All signals have been background subtracted to eliminate the characteristic signal from the device itself with no sample in place. The circled region corresponds to the signal received from the hematoma as the thickness is increased from $0 \mathrm{~mm}$ to $10 \mathrm{~mm}, 24 \mathrm{~mm}$, and $33 \mathrm{~mm}$. Interestingly, it was observed that the amplitude of the peak increases in proportion to the thickness of the hematoma as shown in Figure 12.

\section{FUTURE WORK}

This project will attempt to continue with the prototype device development as follows pending continued funding. By the end of November 1999, we plan to:

1) complete the instrument based impulse radar

2) quantify the signal characteristics suitable for head injury scanning

3) design second antenna prototype for efficient signal coupling to the patient

4) develop signal analysis tools based upon MIR data

In addition, by the end of April 2000, we plan to:

1) finalize the IRB review process at Lawrence Livermore National Laboratory, University of California Davis Medical Center, and John Muir Medical Center collaboration for human trials

2) fabricate a second generation hematoma antenna prototype

3) refine the instrument based radar prototype ready for human tests

4) investigate additional funding sources for continued research and development

5) collaborate with the MIR development team to develop an MIR board designed and dedicated to hematoma detection. 


\section{SUMMARY}

Early diagnosis of potential epi/subdural hematoma is critical for deterring long term disabilities and death of head injury victims. The goal of this project is to develop a device which is:

- a robust, cost effective, first responder screening device to assess high risk individuals for epi/subdural hematoma, for use in both the field and the emergency department.

- a portable, cost effective, continuous means to monitor high risk individuals suspected of having epidural or subdural hematoma and potential secondary insults.

By developing collaborations between highly qualified physicians and scientists, we will be able to develop a clinically relevant device that will be accepted into the standard practices of physicians and field technicians on an accelerated timeline.

The implementation of this device is expected to result in a significant improvement in head injury patient prognosis and simultancously reduce the economic burden to both the patient and the health care provider. Finally, as a supplemental benefit, recent market projections indicate that in the US alone there are 250,000 market sites for the hematoma detector with $\$ 1.5$ billion in potential sales.

\section{ACKNOWLEDGEMENT}

Additional contributions have been made by the following individuals: Davianne Duarte (University of California Irvine), Viviana Acevedo-Bolton (University of California Berkely), Ken Haney (LLNL), George Locke (Drew University of Medicine).

\section{REFERENCES}

S. Jayawant, A. Rawlinson, F. Gibbon, J, Price, J, Schulte, P. Sharples, JR Sibert, AM Kemp, Subdural Haemorrhages in infants:population based study, BMJ 1998 Dec 5;317(7172):1558-61

KS Quayle, DM Jaffe, N Kuppermann, BA Kaufman, BC Lee, TS Park, WH McAlister, Diagnostic testing for acute head injury in childern:when are head computed tomography and skull radiographs indicated? Pediatrics, 1997 May; 99(5):E11.

O De Jesus, H Pacheco, B Negron, Chronic and Subacute Subdural Hematoma in the Adult Population. The Puerto Rico Experience, PR Health Sci J, 1998 Sep; 17(3):227-33.

K Kato, O Watanabe, Y Ozawa, Abrupt Exacerbation of Acute Subdural Hematoma Mimicking benign acute Epidural Hematoma on Computed Tomography-Case Report, Neurol Med Chir (Tokyo) 1999 January; 39(1):33-5.

PE Stieg, CS Kase, Intracranial hemorrhage:diagnosis and emergency management, Neurol Clin, 1998, May; 16(2):273-90

KY Willman, DE Bank, M Senac, DL Chadwick, Restricting the Time of Injury in Fatal Inflicted Head Injuries, Child Abuse Negl, 1997 October; 21(10):929-40.

CS Zee, JL Go, CT of Head Trauma, Neuroimaging Clin N Am, 1998, August;8(3):525-39

MG Wysoki, CJ Nassar, RA Koenigsberg, RA Novelline, SH Faro, EN Faerber, Ilead Trauma: CT Scan Interpretation by Radiology Residents Versus Staff Radiologists, Radiology 1998 July; 208(1):125-8.

MA Vogelbaum, BA Kaufman, TS Park, AL Winthrop, Management of Uncomplicated Skull Fractures in Children: Is Hospital Admission Necessary? Pediatr Neurosurg, 1998, August; 29(2):96-101.

C. Polk and E. Postow, Handbook of Biological Effects of Electromagnetic Fields, $2^{\text {nd }}$ Ed., CRC Press, Inc. 1996 
WS Haddad, ET Rosenbury, KB Johnson, FJ Pearce, JT Chang, Measurement of the Dielectric Properties of Body Tissues and Fluids at Microwave Frequencies, manuscript in preparation

LY Astanin, AA Kostylev, Ultrawideband Radar Measurements- Analysis and Processing, The Institution of Electrical Engineers, London, 1997

DT Gavel, JE Mast, J Warhus, SG Azevedo, Impulse Radar Array for detecting Land Mines, Lawrence Livermore National Laboratory, UCRL-JC-120550, 1995

J Mast, S Azevedo, W Iladdad, L, Ng, G Burnett, Micropower Impulse Radar Technology and Applications, Lawrence Livermore National Laboratory, UCRL-ID 130474, 1998

JP Warhus, SD Nelson, JE Mast, EM Johansson, Advanced Ground-Penetrating, Imaging Radar for Bridge Inspection, Lawrence Livermore National Laboratory, UCRL-JC 113707, 1993

DJ Daniels, Surface-Penetrating Radar, The Institution of Electrical Engineers, I ondon, 1996.

S. Paterniti, MF Falcone, P, Fiore, A, Levita, A La Camera, Is the Size of an Epidural Haematoma Related to Outcome?, Acta Neurochir (Wien) 1998;140(9):953-5.

Kraszewski and Hartsgrove, J. Microwave Power, 1986, 233-240

Kobayashi, et al., IEEE Transaction MTT, 1993, V. 41, no. 1, 136-140) 

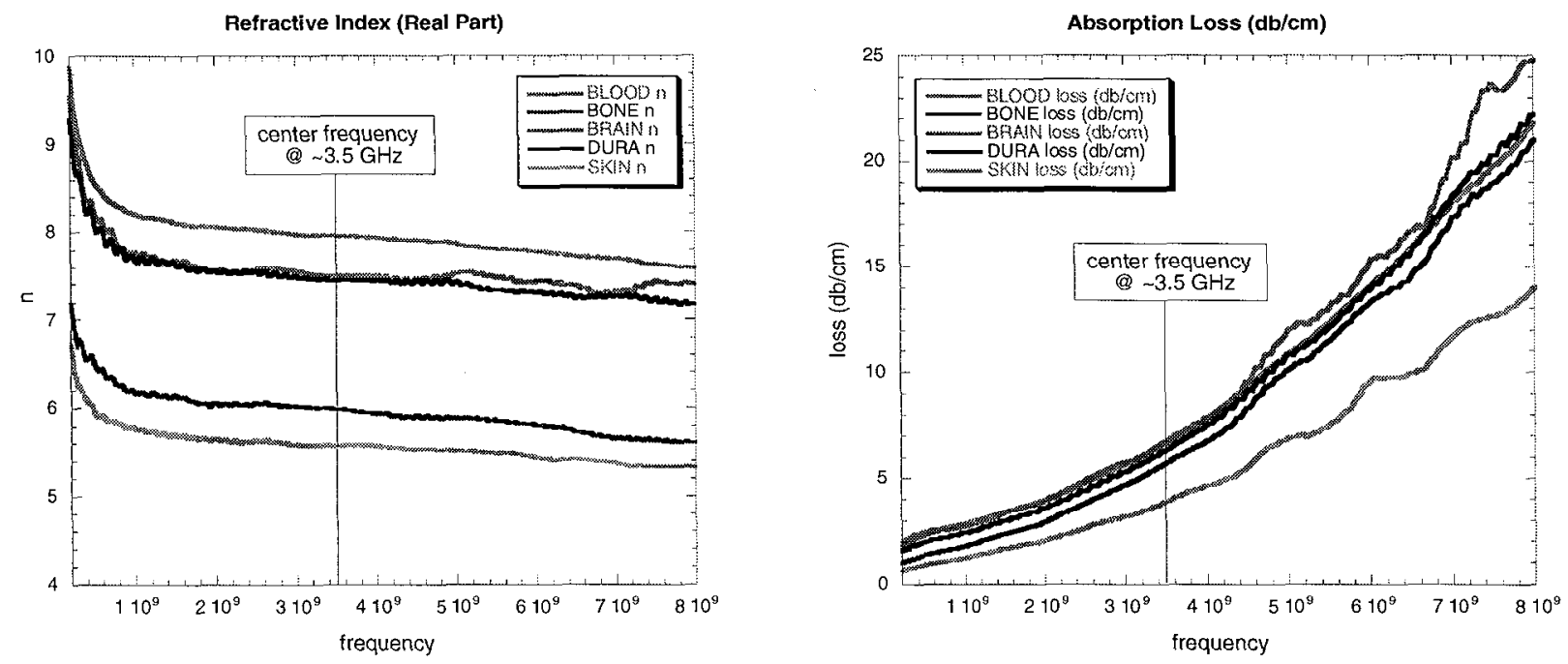

Figure 1 The dielectric properties of the primary tissues contained in the human head. 


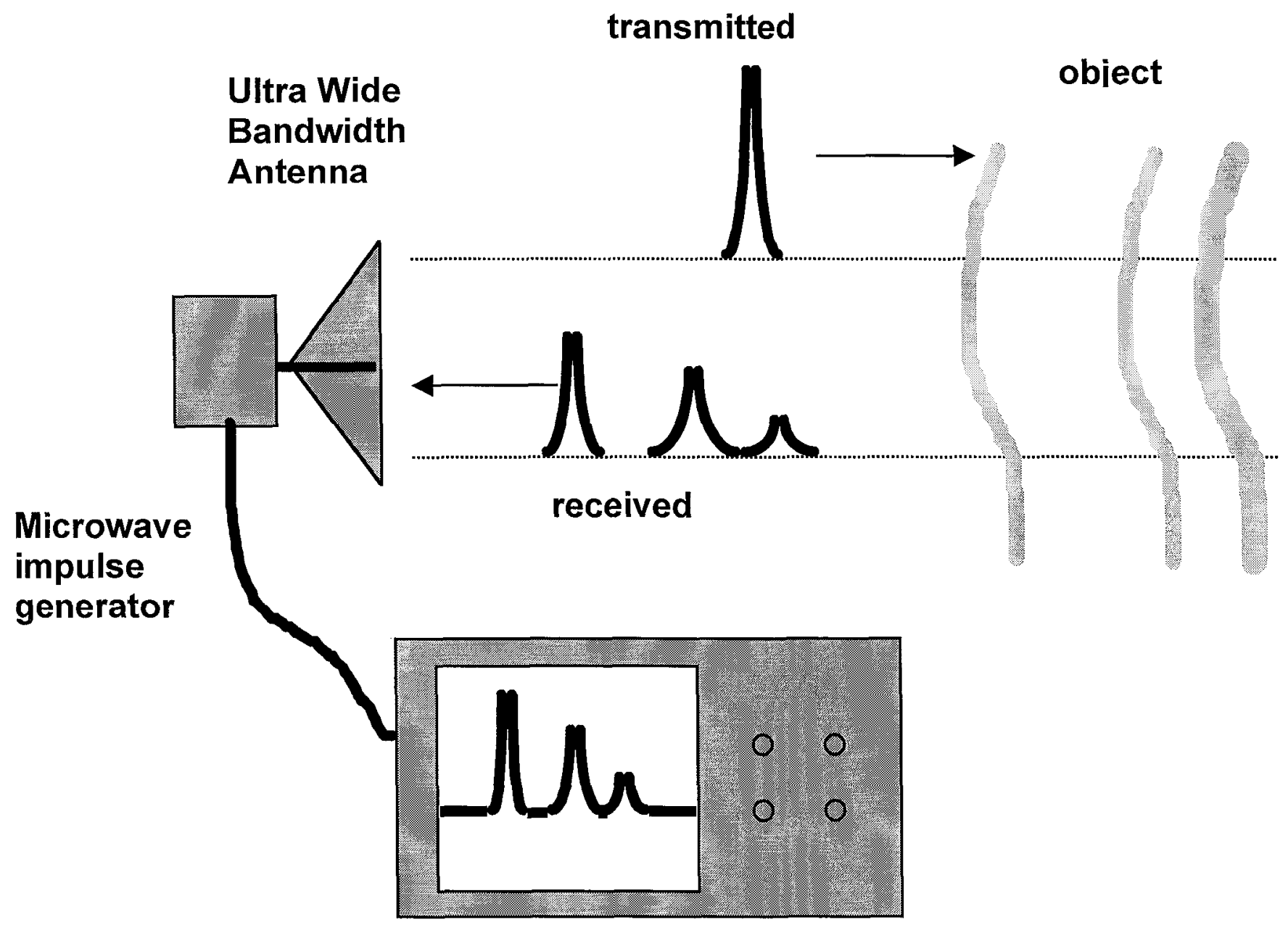

Figure 2. Simple diagram showing how an MIR "range finder" works. 


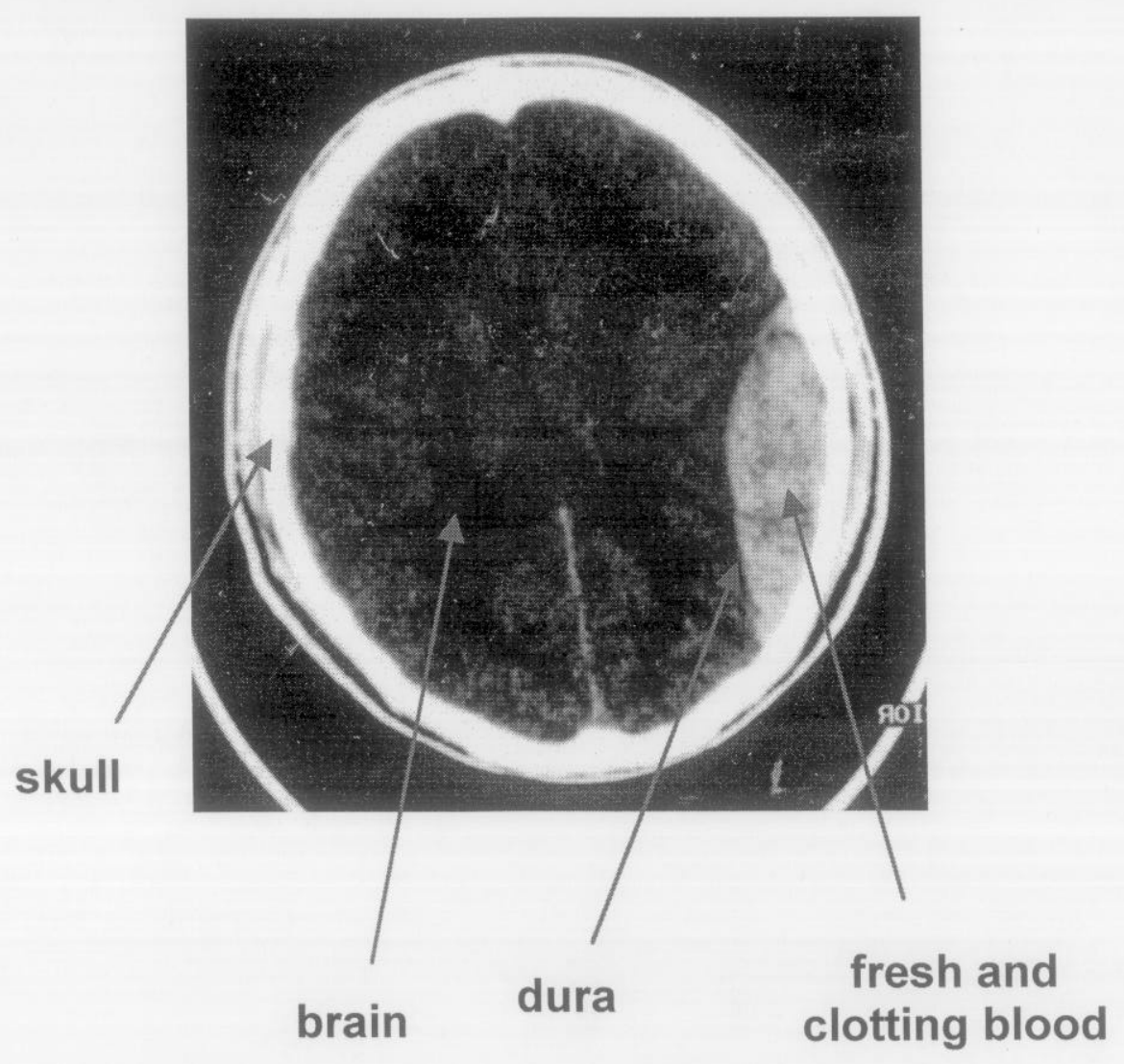

Figure 3a One image from a CT scan of a patient with a large epidural hematoma. 
Region with hematoma: third interface will produce

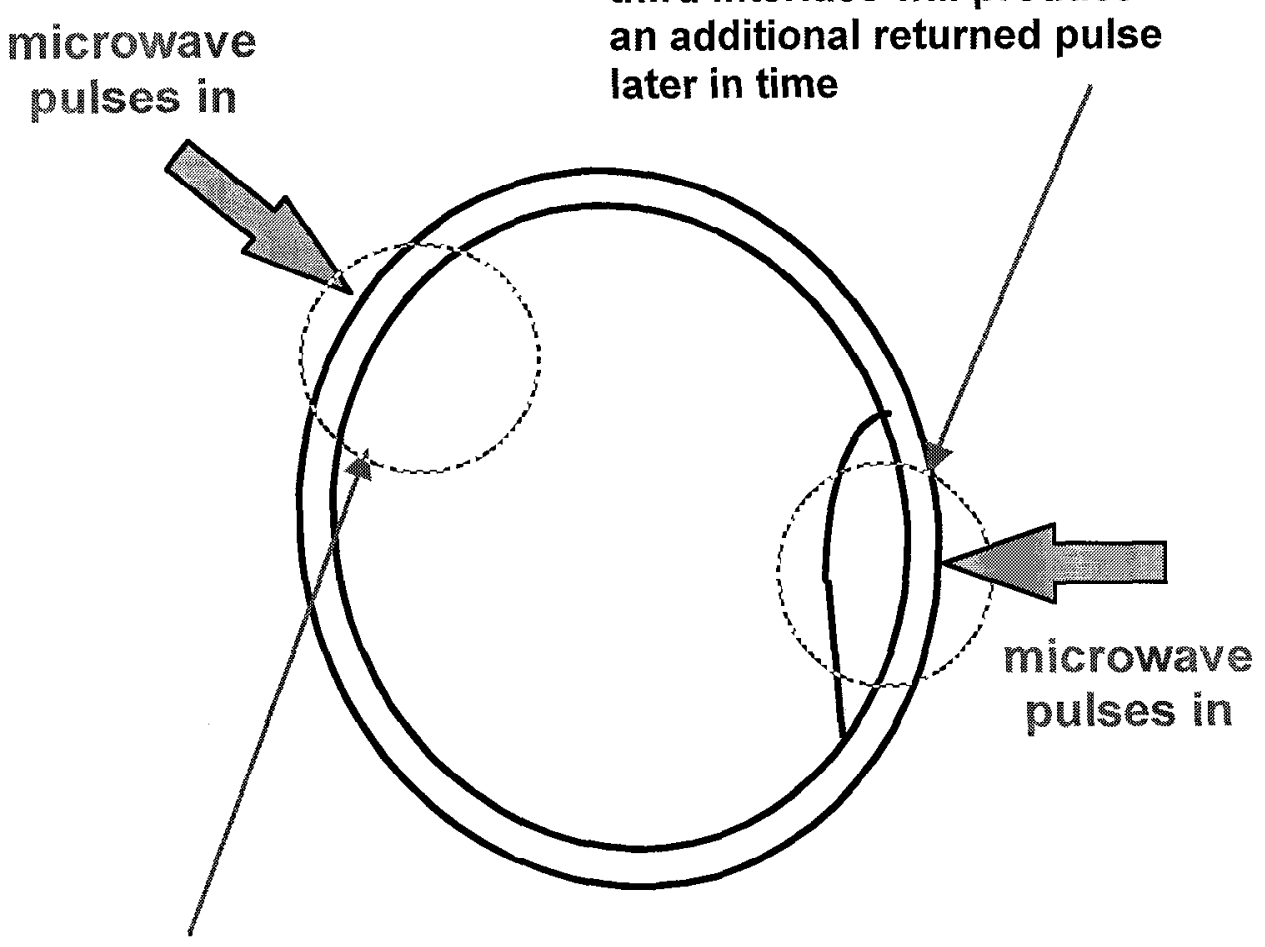

Regions with no

hematoma:

two interfaces will produce two returned pulses close

Figure 3b. Conceptualized schematic of one method by which the hematoma will be detected. 
head/hematoma phantom:

- plastic bowl (skull)

- gelatin filled (brain)

- small plastic bag along wall with fill tube (hematoma)

syringe with water (red) water is injected into bag with syringe to produce the hematoma

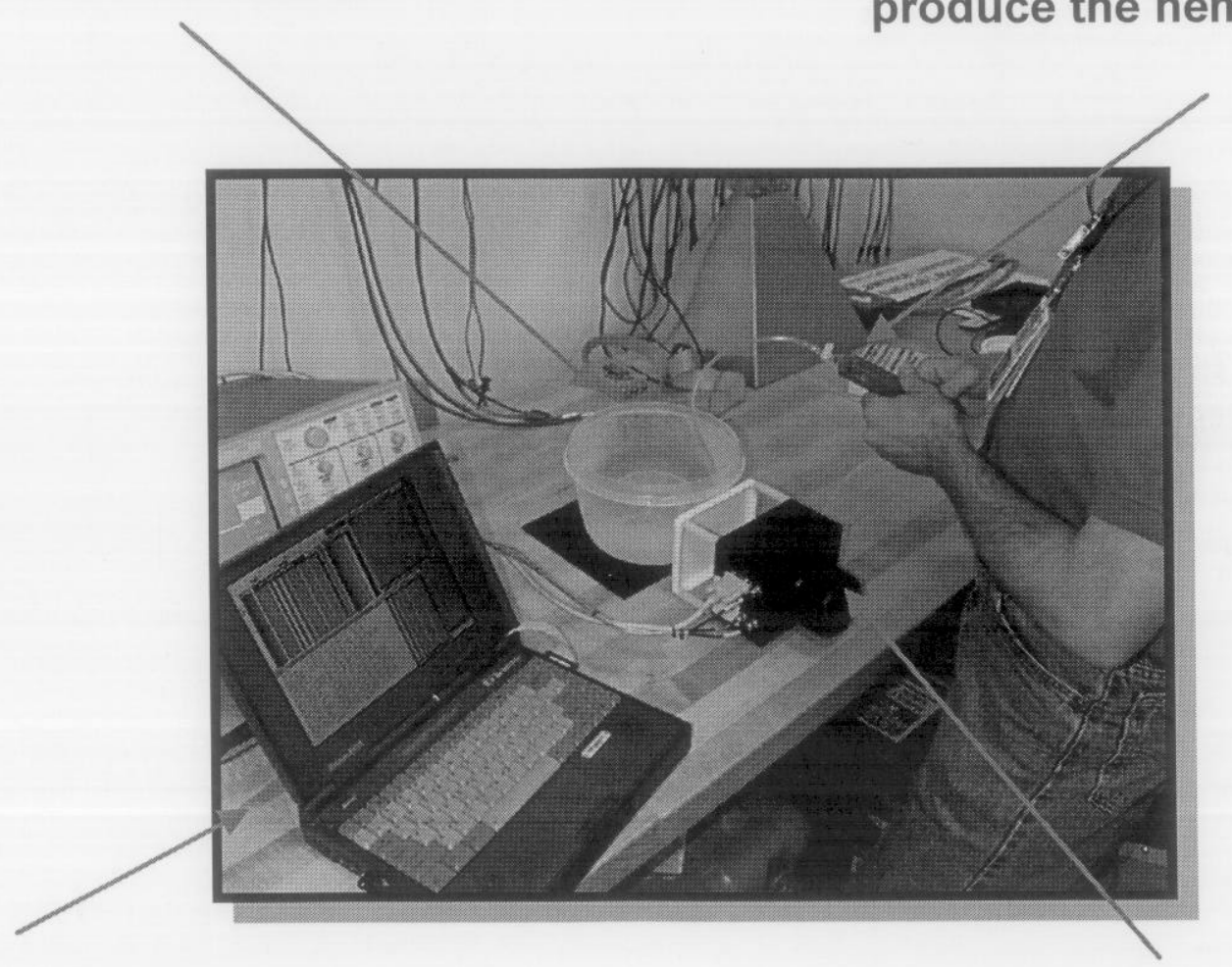

laptop computer

w/DAC card

to record signals
Micro Impulse Radar single antenna device with pulsed output center frequency $\sim 4.5 \mathrm{GHz}$

Figure 4 Early demonstration of concept experimental set up. 

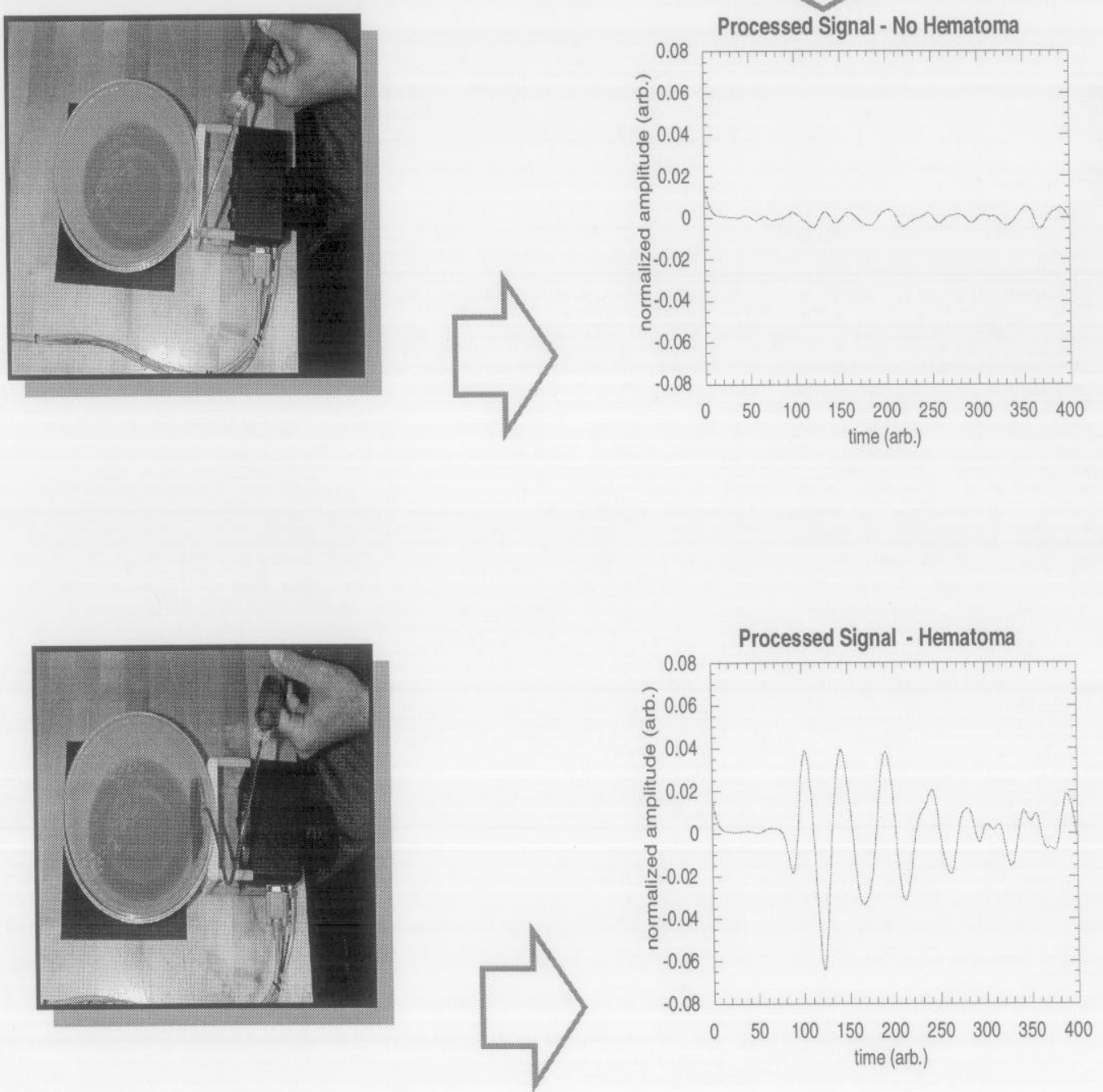

Figure 5 Results of the early demonstration of concept experiments 


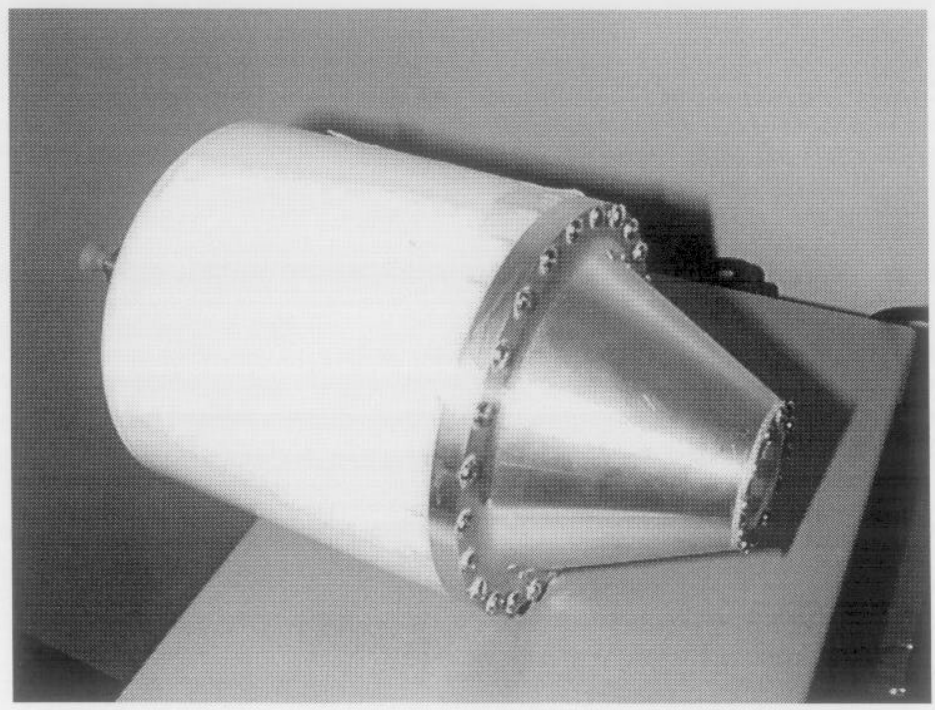

(a)

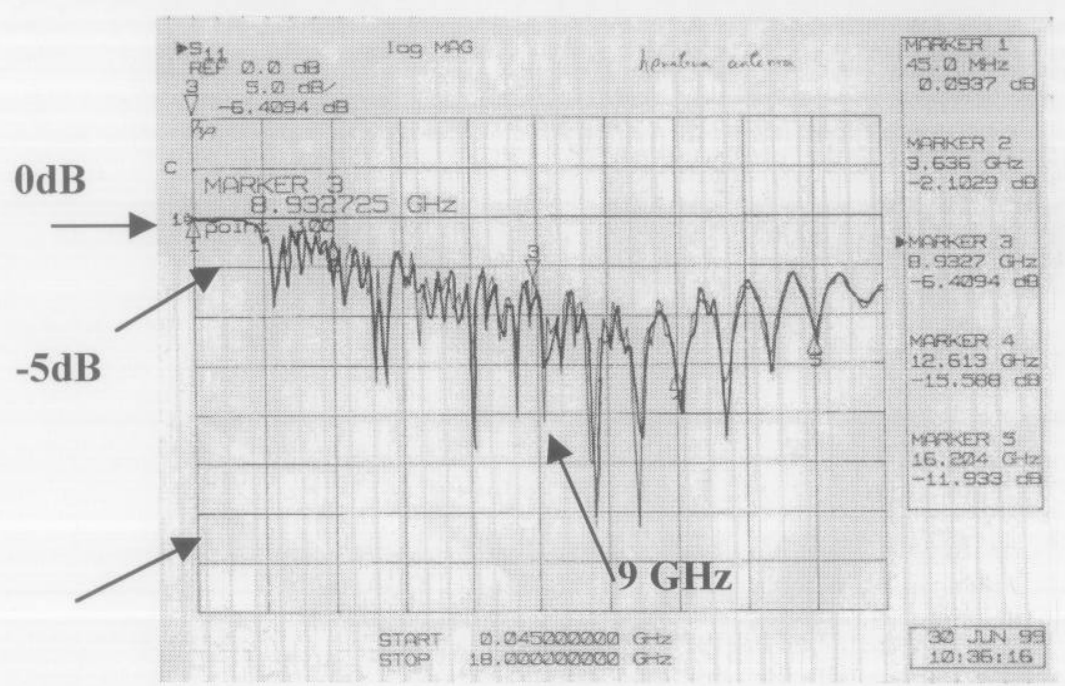

(b)

Figure 6 a) Photograph of the first hematoma detector antenna prototype, b) $S_{11}$ characterization of the antenna 


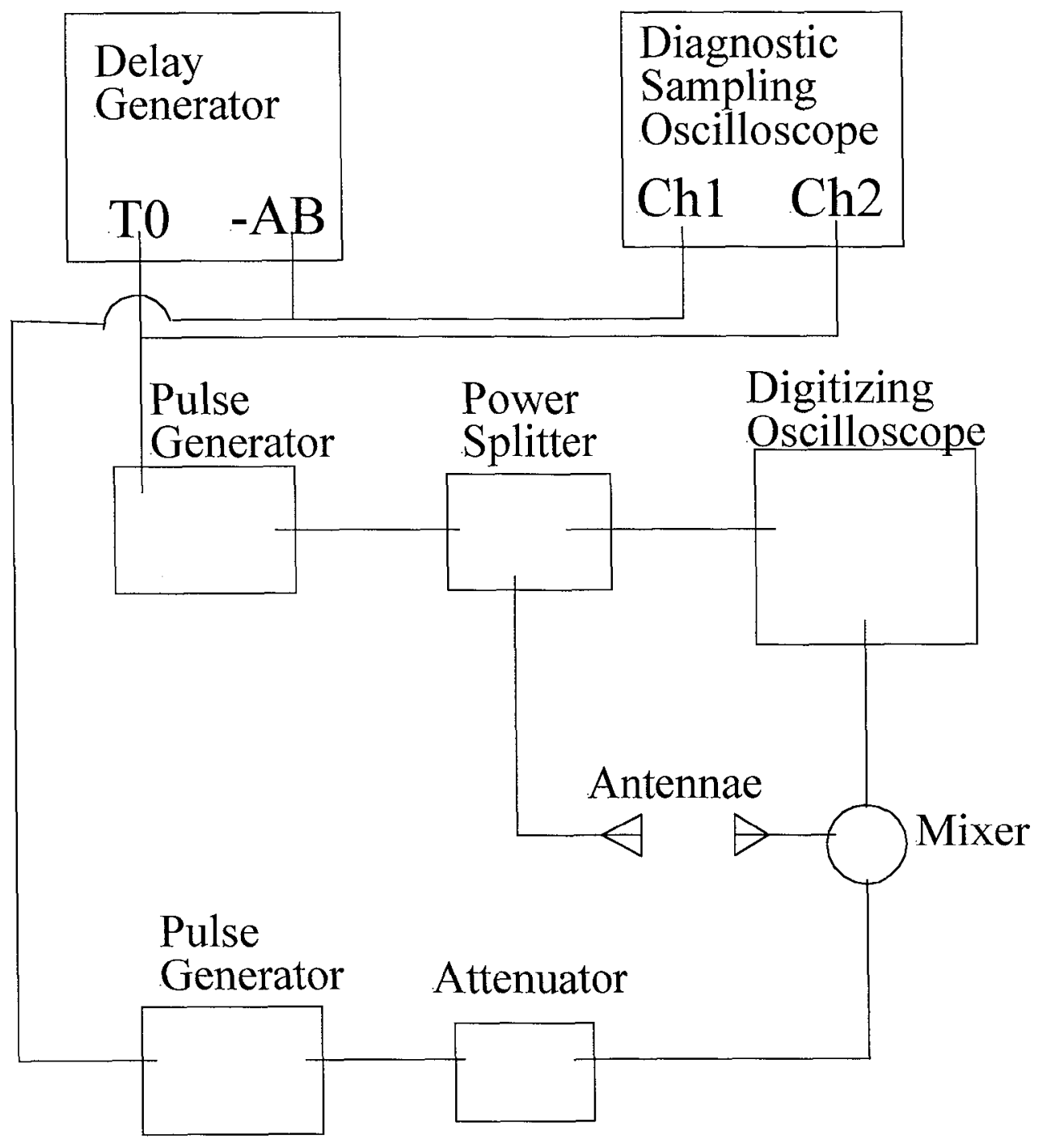

Figure 7 Block diagram of instrument based impulse radar. 


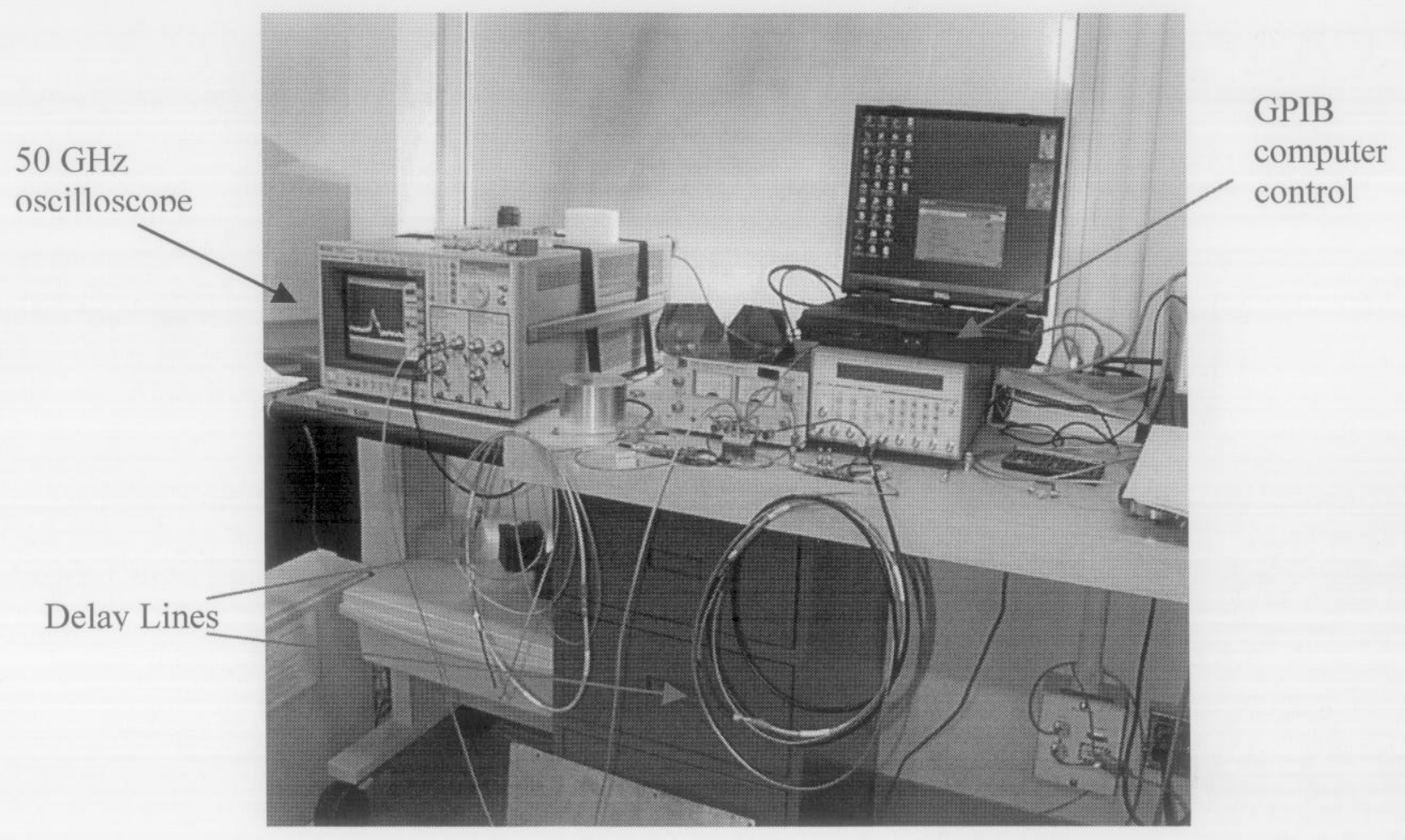

Figure 8 Photograph of the instrument based impulse radar laboratory set up. 


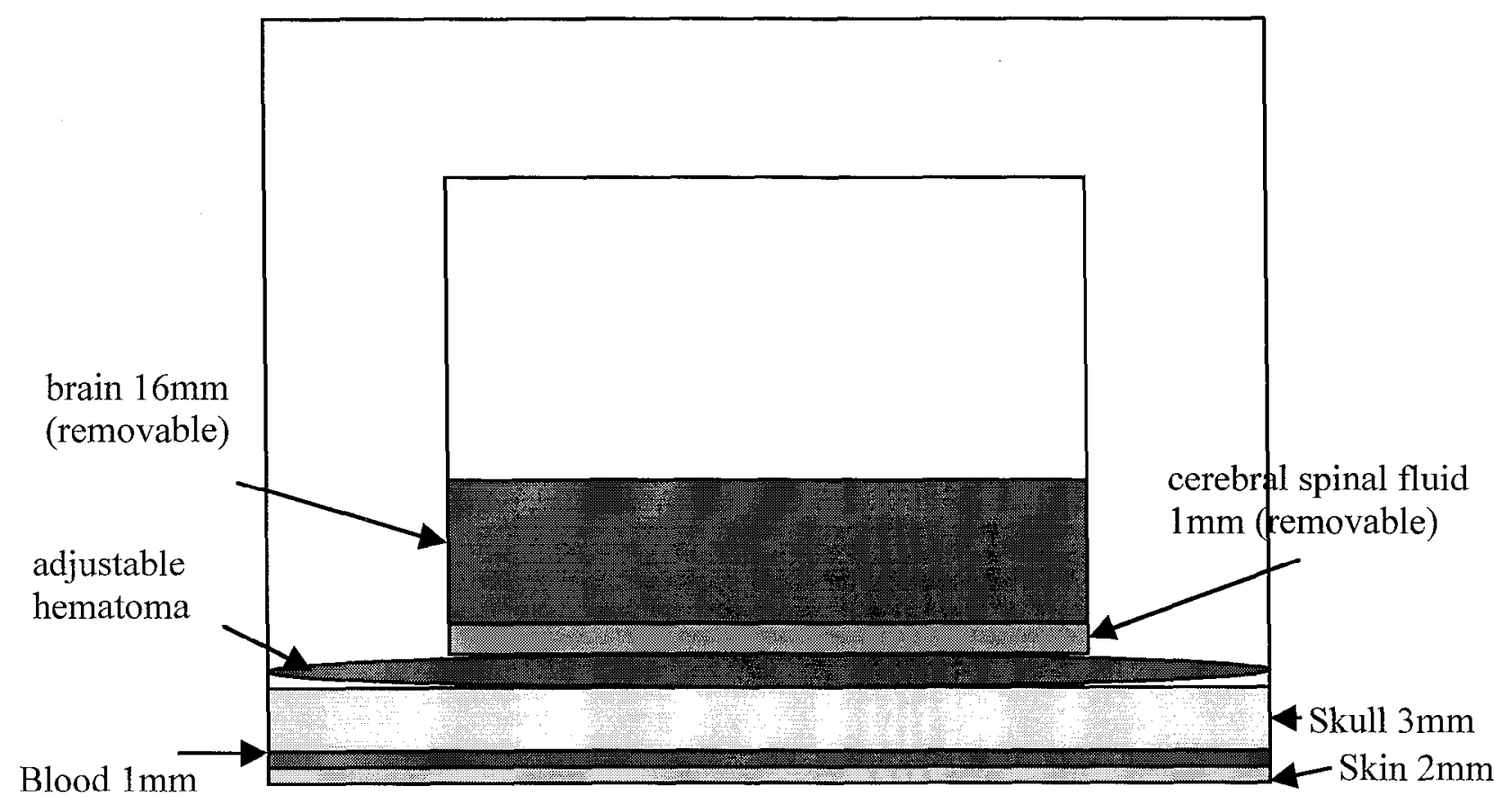

Figure 9 Schematic of the head phantom with adjustable hematoma. 


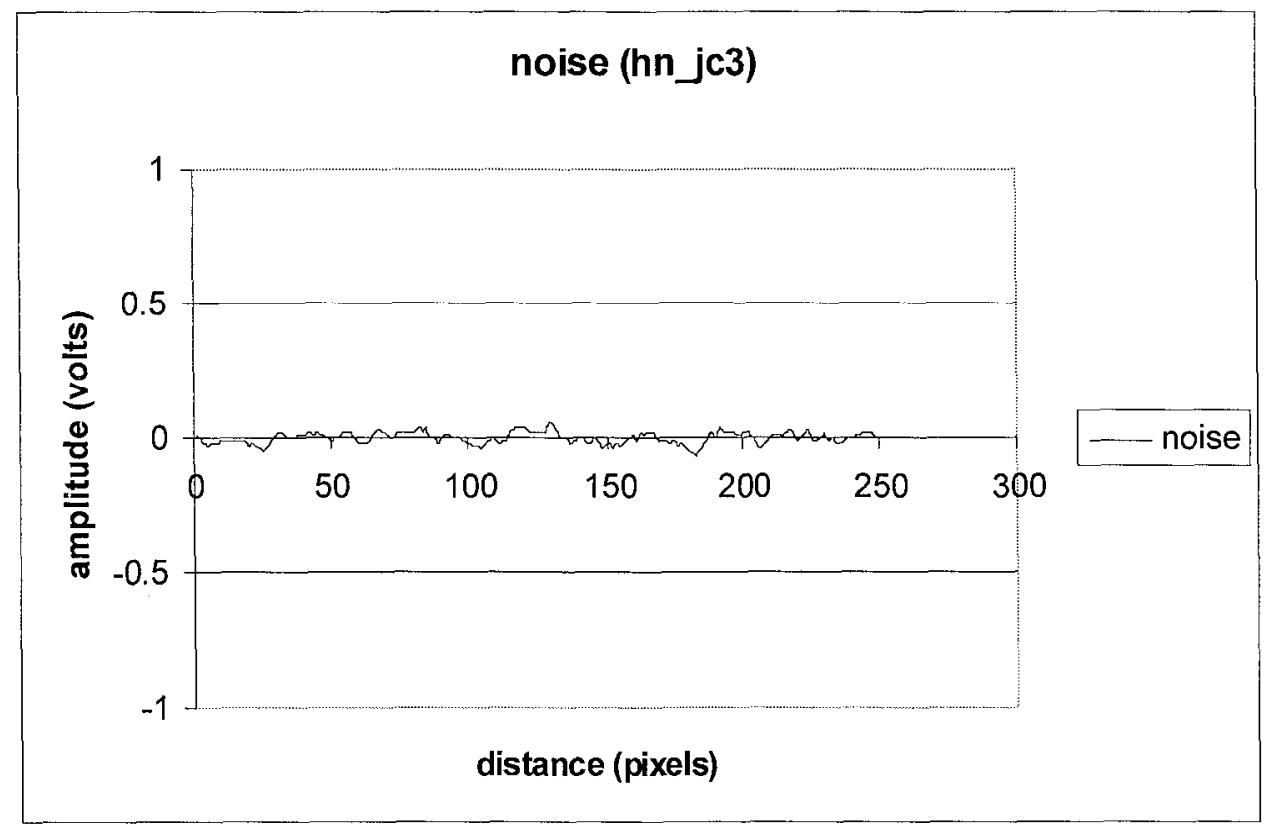

Figure 10 Background noise level in impulse radar system. 


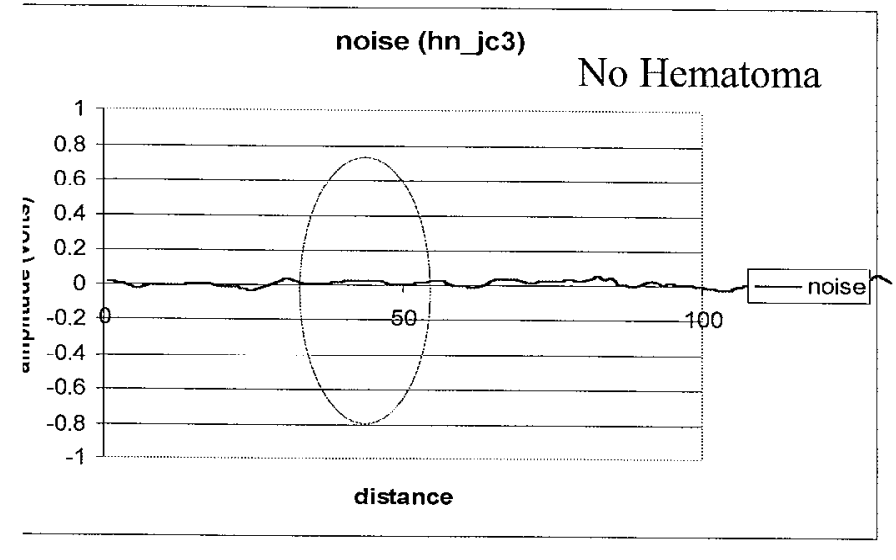

(a)

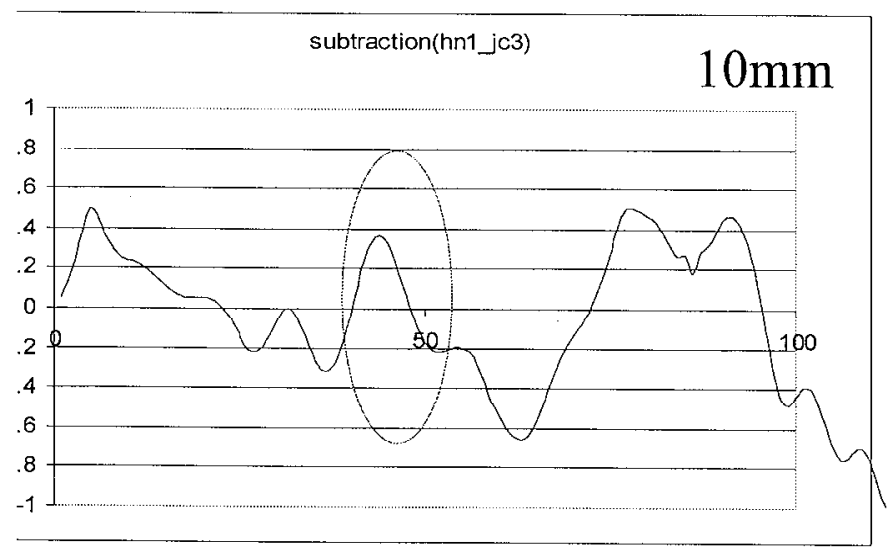

(b)

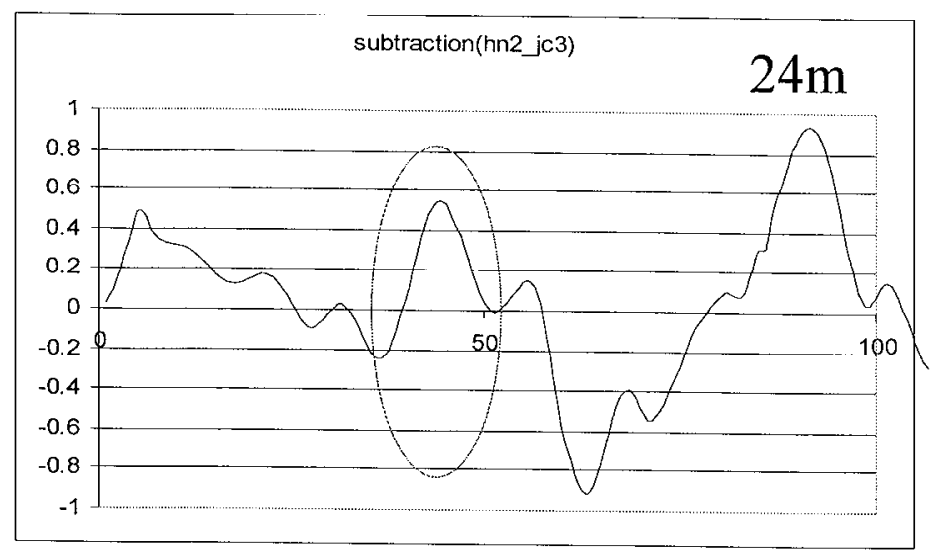

(c)

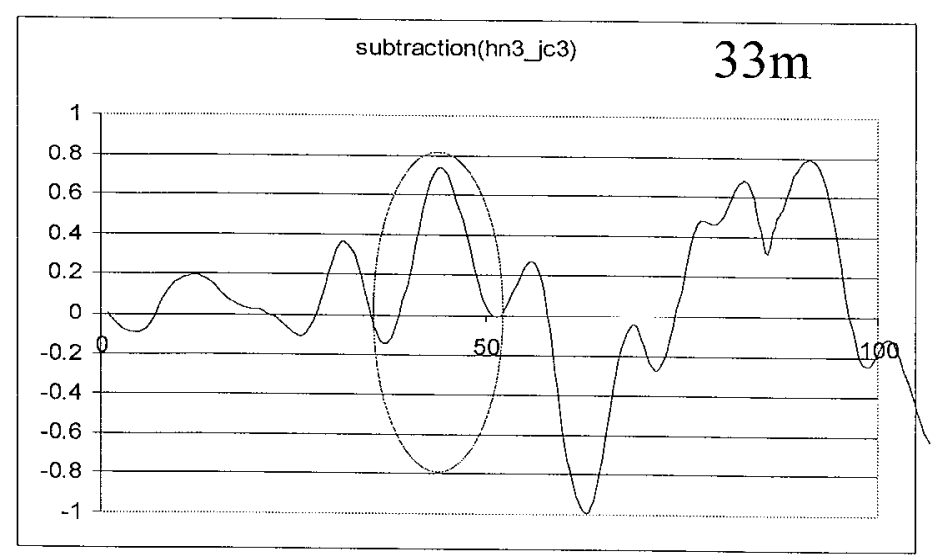

(d)

Figure 11 Results of the phantom hematoma experiment. Background subtraction processed radar scans as function of hematoma thickness. 


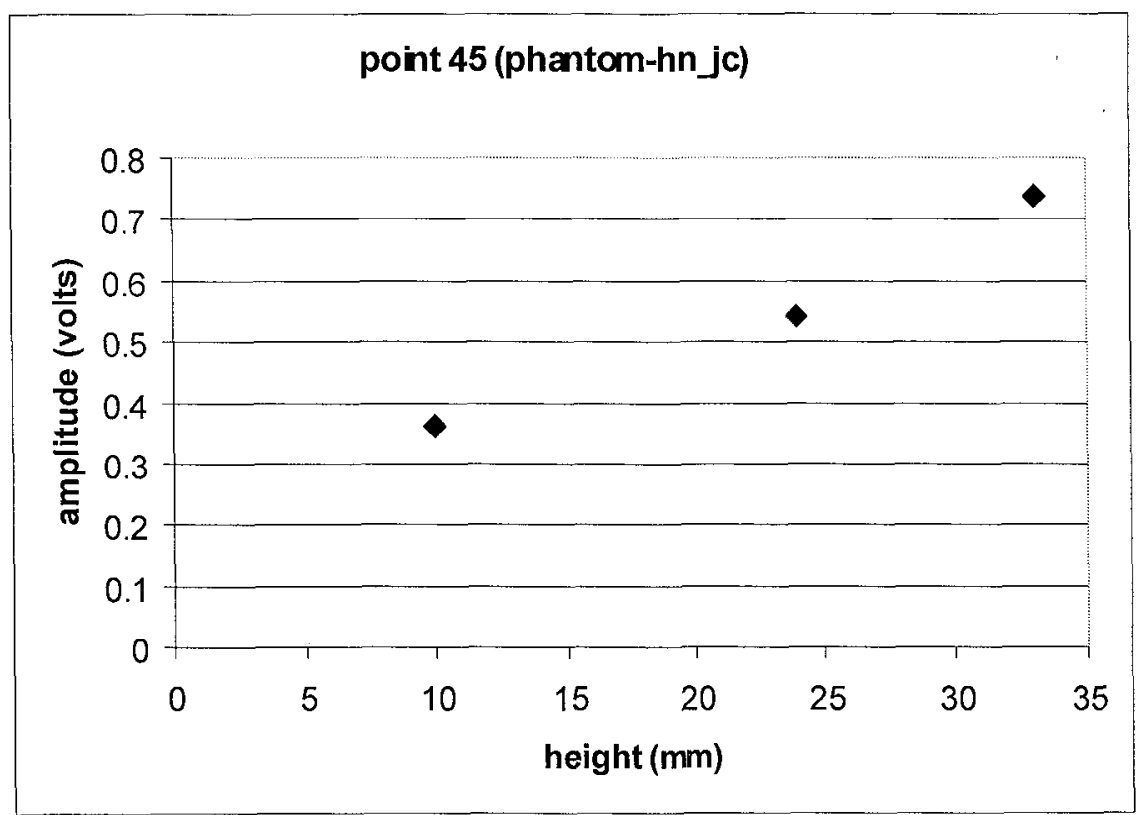

Figure 12 Radar signal amplitude difference as function of thickness of the hematoma. 